\title{
Hot Gunning Robot for Electric Arc Furnace Refractory (the Gun Master)*
}

\section{Introduction}

Godo Steel, Ltd. has developed a hot gunning robot for refractories repairing work of electric arc furnace (called the "Gun Master"trade name) and installed the first machine for a new $70 \mathrm{t}$ electric arc furnace in the Osaka Works in February, 1985. The Gun Master has been operating most intensively since installation, realizing a large saving of manpower and gunning material for repairing the electric arc furnace.

Figure 1 shows the Gun Master at the hot gunning work, and Fig. 2 shows the system configuration.

The result has been so satisfying that the Godo Steel has installed a second Gun Master in the Himeji Works in September, 1986.

\section{Features of the Gun Master}

(1) The Gun Master performs the gunning work automatically according to a program stored in the microprocessor. The operator sets beforehand the range of gunning, gunning thickness, the tilt angle of the gunning nozzle, etc. from the keyboard, and presses the start button. Then, the nozzle base is moved to the furnace center, and gunning work is carried out quickly. After completion of gunning, the gunning nozzle is automatically retracted to and cleaned in the standby position.

(2) The Gun Master is provided with a special mixer that optimizes the powder to water ratio for the consistency desired, so that water is minimized.

(3) The revolution center of the gunning nozzle for the Gun Master may be moved up or down along the furnace center line. Consequently, optimum gunning is assured in any direction in the furnace.

(4) The gunning nozzle can be tilted freely so that the Gun Master can gun refractories onto the lower side wall, the slag line, etc., except for the dead center part of the hearth bottom. For example, the inside wall near slagging doorway, where manual gunning is difficult by any conventional methods, can now be easily gunned. In addition, the Gun Master is most suitable for gunning work in high temperature atmospheres.

(5) The structure of the Gun Master is so compact and simple that only one operator can perform all the gunning work.

\section{Reduction of Consumption of Gunning Material Using Gun Master}

After installing the Gun Master, reduction of about $2 \mathrm{~kg} / \mathrm{t}$ (about $30 \%$ ) in the consumption of the gunning material has been achieved compared with manual gunning work.

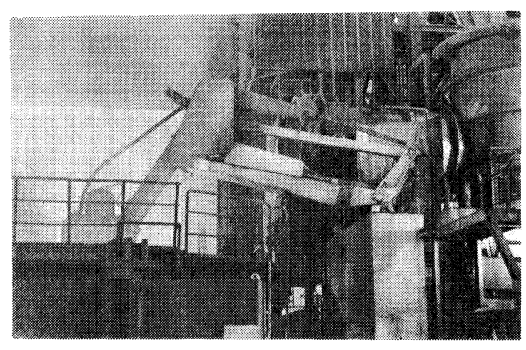

Fig. 1. Hot gunning work by Gun Master.

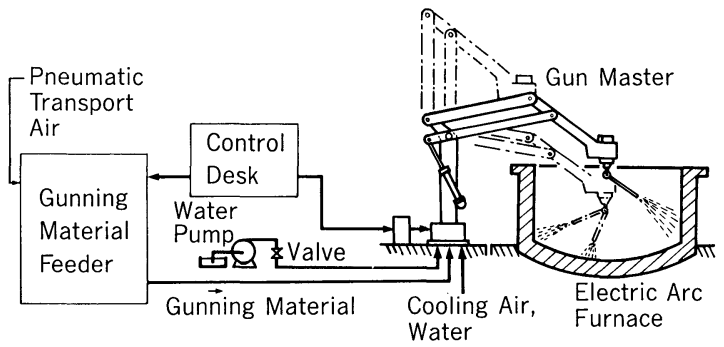

Fig. 2. Schematic system diagram of Gun Master.

* For further information, write to Production Technical Department, Godo Steel, Ltd., 3-24, 2-chome, Umeda, Kita-ku, Osaka 530. (C) 1987 ISIJ 